Available online at https://jurnal.stmikroyal.ac.id/index.php/jurdimas

\title{
PELATIHAN PEMBUATAN MEDIA PEMBELAJARAN BERBASIS POWER POINT PADA LEMBAGA KURSUS PENDIDIKAN (LKP) MANDIRI COMPUTER
}

\author{
Arridha Zikra Syah ${ }^{1 *}$, William Ramdhan ${ }^{1}$, Uswatun Hasanah ${ }^{1}$, Rolly Yesputra ${ }^{2}$ \\ ${ }^{1}$ Sistem Informasi, STMIK Royal Kisaran \\ ${ }^{2}$ Sistem Komputer, STMIK Royal Kisaran \\ email: ${ }^{*}$ azsyra@gmail.com
}

\begin{abstract}
Lembaga Kursus Pendidikan (LKP) is an educational institution engaged in office application training. They has good modules. But the modules dont consit the real aplication. Exspecially, the module of the power point has not include the real world practice yet. The method are used in this activity in the form of description of the material and practice. The speaker made explanations about the application of Microsoft Power Point 2010, then utilizing the results of Microsoft Power Point 2010 applications, so that they are interesting as well as examples of their application in business applications. after that practice directly using the application. Some important points are explained and practiced in this activity, namely the design of interactive learning media, how to arrange the display to be interesting, and the addition of tools integrated in power points, conversion to videos. Community service activities at the Lembaga Kursus Pendidikan (LKP) completed on 5-6 October 2018 and attended by twenty students, two tutors and three administrative staff. The material delivered to participants reached $90 \%$ of all multimedian concepts and learning media. Based on the results of the discussion and testing of the participants through questions and discussion, that $\pm 95 \%$ had mastered and understood the material presented.
\end{abstract}

Keywords: Interactive Learning Media, Microsoft Power Point, Video Tutorial

\begin{abstract}
Abstrak: Lembaga Kursus Pendidikan (LKP) Mandiri merupakan lembaga pendidikan yang bergerak dalam pelatihan aplikasi perkantoran. Lembaga Kursus Pendidikan memiliki sudah modul yang bagus. Namun dalam penerapan aplikasi perkantoran di dunia nyata belum dibahas khususnya untuk Microsoft Power. Metode yang digunakan dalam kegiatan ini adalah deskripsi materi dan praktek. Pemateri melakukan penjelasan-penjelasan tentang aplikasi Microsoft Power Point 2010, pemanfaatan hasil aplikasi Microsoft Power Point 2010 sehingga menarik serta contoh-contoh penerapannya dalam aplikasi bisnis, setelah itu praktek langsung menggunakan aplikasi tersebut. Beberapa point penting yang dijelaskan serta dipraktekkan dalam kegiatan ini, yaitu perancangan media pembelajaran interaktif, cara merangkai tampilan agar menarik, dan penambahan tool terintegrasi pada power poin, konversi ke vidio. Kegiatan pengabdian kepada masyarakat pada Lembaga Kursus Pendidikan (LKP) Mandiri Computer Telah selesai dilaksanakan tanggal 5-6 Oktober 2018 dan dihadiri oleh peserta didik sebanyak dua puluh orang, tutor sebanyak dua orang serta bagian administrasi sebanyak tiga orang. Materi yang disampaikan kepada peserta mencapai $90 \%$ dari semua konsep multimedian dan media pembelajaran. Berdasarkan hasil pembahasan dan dilakukannya pengujian terhadap peserta dengan melalui pertanyaan-pertanyaan dan diskusi, bahwa $\pm 95 \%$ telah menguasai dan memahami materi yang disampaikan.
\end{abstract}

Kata kunci: Media Pembelajaran Interaktif, Microsoft Power Point, Vidio Tutorial 
Available online at https://jurnal.stmikroyal.ac.id/index.php/jurdimas

\section{PENDAHULUAN}

Lembaga Kursus Pendidikan (LKP) Mandiri merupakan lembaga pendidikan yang didirikan tahun 2011. Lembaga ini memberikan pelatihan mengenai dasar penggunaan aplikasi komputer melalui pelatihan aplikasi perkatoran seperti microsoft office. Seperti sekolah pada umumnya lembaga ini dilengkapi dengan fasilitas yang memadai, satu komputer untuk per individu setiap kali praktek. Selain itu, lembaga ini juga telah memiliki modul ajar yang baik dan lengkap mengenai panduan penggunaan tiap-tiap aplikasi.

Walaupun Lembaga Kursus Pendidikan memiliki modul yang bagus. Namun dalam penerapan aplikasi perkantoran di dunia nyata belum dibahas khususnya untuk Microsoft Power. Aplikasi ini bukan hanya digunakan untuk presentasi saja. Namun ada penerapan menarik lainnya yang bisa dibuat oleh peserta kursus pada lembaga kursus pendidikan (LKP) Mandiri Computer, seperti media interaktif, vidio tutorial dan lain sebagainya.

Berdasarkan dasar pemikiran diatas maka kami mengajukan proposal pengabdian masyarakat kepada Lembaga Penelitian dan Pengabdian pada Masyarakat (LPPM) STMIK Royal Kisaran sebagai sarana pengembangan transfer ilmu untuk mendapat persetujuan penyelenggarakan kegiatan Pengabdian Masyarakat dengan judul "Pelatihan Pembuatan Media Pembelajaran Berbasis Power Point Pada Lembaga Kursus Pendidikan (LKP) Mandiri Komputer".

Berdasarkan permasalahan yang terjadi dan telah diuraikan pada bab sebelumnya, maka solusi paling efektif adalah Membuat salah satu aplikasi interaktif dalam bentuk media pembelajaran sebagai salah satu implementasi dari aplikasi Microsoft Power, Memberikan pelatihan pembuatan vidio yang mudah melalui integrasi Microsoft Power dan Menyediakan modul dan tutorial penggunaan pembuatan aplikasi media pembelajaran interaktif melalui Microsoft Power untuk peserta yang mengikuti kegiatan pengabdian kepada masyarakat.

\section{METODE}

Tahapan atau langkah-langkah yang ditempuh agar terlaksana dengan baik dan lancar serta tercapainya tujuan kegiatan pengabdian kepada masyarakat ini adalah:

1. Mempersiapkan materi yang akan diberikan, baik modul, slide presentasi, dan alat peraga lainnya.

2. Memastikan tempat dan fasilitas pendukung seperti in focus, projector, dan lain-lain sudah standby pada saat kegiatan akan dilangsungkan.

3. Menjelaskan teori tentang materi aplikasi Microsoft Power Point 2010.

4. Praktek langsung pada komputer atau laptop dalam media pembelajaran interaktif menggunakan aplikasi Microsoft Power Point 2010.

5. Diskusi dan tanya jawab.

Dalam kegiatan ini pimpinan Lembaga menyediakan tempat selama kegiatan dilangsungkan dan fasilitasfasilas penunjang yang mereka miliki untuk mendukung kegiatan ini berjalan dengan baik dan lancar.

Setelah kegiatan pengabdian 
Available online at https://jurnal.stmikroyal.ac.id/index.php/jurdimas

kepada masyarakat ini dilakukan, maka langkah selanjutnya adalah Tim pengabdian kepada masyarakat melakukan monitoring selama 3 sampai 3 kali pada Lembaga Kursus Pendidikan (LKP) Mandiri Computer, untuk memastikan para peserta didik sudah benar-benar mampu mengimplementasikan aplikasi Microsoft Power Point 2010 dalam berbagai kasus secara maksimal atau masih belum. Jika belum maka Tim akan membantu mengingat-kan kembali. Tinjauan ini dilakukan setiap satu kali dalam seminggu pasca kegiatan.

\section{PEMBAHASAN}

\section{Peserta Kegiatan}

Kegiatan pengabdian kepada masyarakat pada Lembaga Kursus Pendidikan (LKP) Mandiri Computer Telah selesai dilaksanakan di Laboratorium LKP Mandiri Computer dengan topik pelatihan pembuatan media interaktif dalam bentuk suatu Pembuatan Media Pembelajaran Berbasis Power Point pada tanggal 5-6 Oktober 2018 dan dihadiri oleh peserta didik sebanyak dua puluh orang, tutor sebanyak dua orang serta bagian administrasi sebanyak tiga orang.

\section{Materi Kegiatan}

a. Teoritis

Media pembelajaran dapat dikatakan sebagai alat- alat grafis, photografis, atau elektronis, yang dapat digunakan untuk menangkap, memproses, dan menyusun kembali informasi visual atau verbal atau merupakan komponen sumber belajar atau wahana fisik yang mengandung materi instruksional di lingkungan siswa yang dapat merangsang siswa untuk belajar (Syah et al. 2018).

Media pembelajaran berkembang dari waktu ke waktu, seiring dengan perkembangan teknologi. Bebe-rapa ahli menggolongkan macam- macam media pembelajaran dari sudut pandang yang berbeda.

Media pembelajaran dalam bukunya meliputi: nonprojected media, projec-ted media, audiomedia, motionmedia, computer mediated instruction, computer based multimedia and hypermedia, media radio and television. Nonprojected media berupa photographs, diagrams, displays, dan models. Projectedmedia terdiri dari slides, filmstrips, overhead transparencies, dan computer projection. Audiomedia berupa cassettes dan compact discs, sedangkan motionmedia berupa video dan film. (Naz 2008)

Arsyad(2011) mengelompokkan media pembelajaran menjadi empat kelompok, yaitu media hasil teknologi cetak, media hasil teknologi audio visual, media hasil teknologi komputer, dan media hasil gabungan teknologi cetak dan komputer.

Berdasarkan macam-macam media tersebut di atas, menunjukkan bahwa media pembelajaran senantiasa mengalami perkembangan seiring kemajuan ilmu dan teknologi. Perkembangan media pembelajaran juga mengikuti tuntutan dan kebutuhan pembelajaran, sesuai dengan situasi dan kondisi yang ada (Sutirman,2013).

Levie \& Lents dalam Azhar Arsyad (2007) mengemukakan empat fungsi media pembelajaran, khususnya media visual, yaitu fungsi atensi, fungsi afektif, fungsi kognitif, dan fungsi kompenstoris.

Media pembelajaran interaktif adalah media pembelajaran yang 
Available online at https://jurnal.stmikroyal.ac.id/index.php/jurdimas

berbasis komputer. media ini menggabungkan dan mensinergikan semua media yang terdiri dari teks, grafis, foto, video, animasi, musik, narasi, dan interaktivitas yang diprogram berdasarkan teori pembelajaran (Nandi dalam (Hamadin 2015)Hamadin, dkk., 2006: 7).

Minat siswa untuk mengikuti pembelajaran yang berlangsung. Petunjuk-petunjuk dan tombol interaktif yang tersedia di dalam media pembalajaran interaktif mudah untuk digunakan serta kontenkonten yang terdapat didalam media tersebut sangat bermanfaat dalam menambah pengetahuan siswa (Hamadin 2015). Model media pembelajaran interaktif, diantaranya adalah model praktik dan latihan (drill and practice), tutorial, permainan (games), simulasi (simulation), penemuan (discovery), dan pemecahan masalah (problem solving) (Daryanto, 2011: 132)

\section{b. Tahapan Pembuatan Media Pembelajaran Menggunakan Microsoft Powe Point \\ 1. Mendesain Template}

Tahapan pembuatan template dijabarkan sebagai berikut: 1) Buka program Ms PowerPoint 2007; 2) desainlah background untuk tampilan slade anda, anda boleh menggunakan shape, chart, smartArt, yang berada di menu insert; 3) jika anda menggunakan gambar sebagai background carilah gambar yang sesuai dengan tema yang anda singgung dalam tutorial anda. Atau secara default anda bisa menggunakan background yang sesuai dengan template power point. Power point menyediakan template-template yang cukup menarik.; 4) Kemudian tambahkan icon interaktif pada slade berupa panel-panel. Icon interaktif bisa dipilih dari shape pada menu insert. Untuk menampil kesan interaktifnya anda dapat memberikan pengaturan emboss dengan memberikan pengaturan pada menu format, shapes effect, bevels; 5) Tambahkan icon home, next ( $\rightarrow$ ), Back $(\leftarrow)$ dan close atau exit ( $\mathrm{x}$ ) seperti pada gambar contoh template.

2. Mengatur Master Slide

Cara termudah untuk membuat perubahan yang sama untuk semua slide atau slide yang menggunakan tata letak tertentu adalah mengubah slide master, juga disebut master slide. Sebagai contoh, bayangkan bahwa Anda seperti sebuah tema, tapi ingin mengubah elemen desain tertentu dari tema. Anda mungkin ingin gaya bullet yang berbeda, judul slide yang pusat margin bukannya kiri, atau aksen garis di bawah judul masing-masing slide. Anda dapat dengan cepat membuat perubahan ini dan lebih dengan memodifikasi slide master.

Tahap mengubah master slide adalah dengan memilih tab [View] lalu Klik perintah [Slide Master] di grup [Presentation Views] dan Tab Master slide akan muncul sebagai tab aktif di Ribbon, dan task pane master slide akan muncul di sebelah kiri.

Tampilan slide master muncul mirip dengan tampilan normal, namun pada tampilan slide master objek akan ditampilkan dalam panel dari slide yang sebenarnya. Gambar kecil pertama di task pane di sebelah kiri adalah slide master yang mengontrol semua slide. Jika Anda ingin membuat perubahan ke semua slide dalam presentasi, Anda dapat melakukannya dengan mengubah slide ini.

Setiap slide di bawah slide master adalah master slide untuk mendukung tata letak. Misalnya, jika 
Available online at https://jurnal.stmikroyal.ac.id/index.php/jurdimas

Anda ingin membuat perubahan ke semua slide dengan menggunakan judul dan isi tata letak, Anda dapat melakukannya dengan menggunakan tata letak Judul dan Isi master slide pada taskpane.

3. Memberikan Action Pada Menu

1) Masuk ke Slide Master, Klik View $>$ Slide Master

2) Klik menu yang diinginkan Klik Insert > Action

3) Pilih Hyperlink to $>$ Slide $x x x$ (xxx pilihlah sesuai dengan urutan slide diatas, yaitu slide 2) $>\mathrm{OK}$

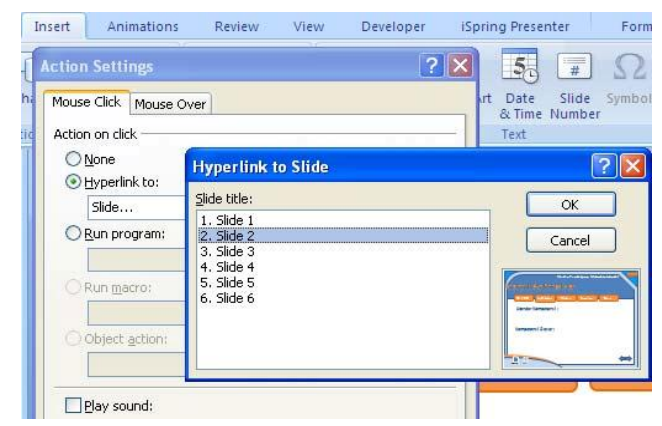

Gambar 1 Hyperlink to Slide

4) Ulangi untuk menu-menu berikutnya

5) Pada menu Home >klik kanan > Klik Action settings hyperlink to > First Slide

6) Pada menu Exit > klik kanan > Klik Action settings $>$ End Show

7) Pada menu Next dan previous $>$ klik kanan > Klik Action settings > Pilih Previous slide atau next slide

8) Kalau sudah keluar dari slide master kembali ke Normal caranya: Klik

View > Normal

9) Cobalah dengan tekan F5 atau Slide Show $>$ From Beginning

10) Klik Office Button > Save As dan beri nama file pada kotak file name.

4. Mempublish File dengan iSpring Presenter

File yang telah dibuat tersebut jika dijalankan (Slide Show), menu quiz belum dapat berjalan. Hal ini disebabkan quiz tersebut masih berupa file iSping Presenter. Supaya quiz tersebut dapat dijalankan maka file .pptx tersebut harusdipublih terlebih dahulu dengan iSpring Presenter. Langkahnya adalah Klik menu iSpring Presenter > Publish. Pada Jendela Publish to Flash, klik web > General > Presentation Tittle. Lalu Beri nama Presentation Title misal MediaPembelajaran Interaktif. Kemudian Pada bagian Destination, klik My Computer dan tetukan lokasi folder untuk menyimpan file pada kotak Local Folder, dan beri nama file nya pada kotak File Name (misal Media Pembelajaran Interaktif). Dan Pada bagian Slide Range pilih All Slide. Pada bagian Flash Output, klik Presentation > All in one Flash file (untuk mengubah file .pptx menjadi file .swf). Terakhir Klik Generate EXE ( untuk mengubah file .pptx menjadi file executable(.EXE)).

Jika Flash Output hanya memilih All in one Flash File, maka file yang didapatkan adalah file flash movie atau file .swf saja, jika flash output yang dipilih All in one Flash file dan Generate EXE maka file yang didapatkan hanya file executable (file .exe)

A. Dokumentasi Kegiatan

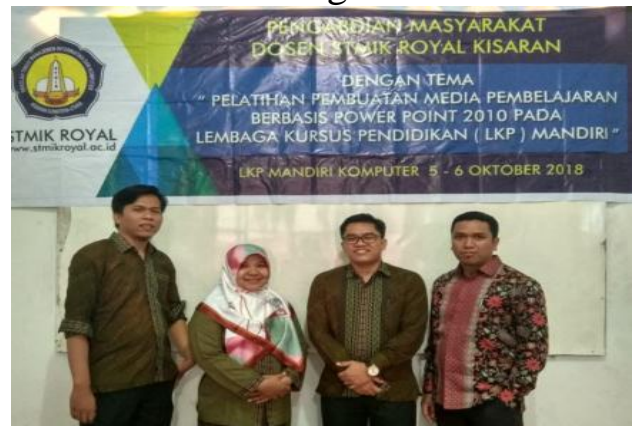

Gambar 2. Tim Pengabidan 

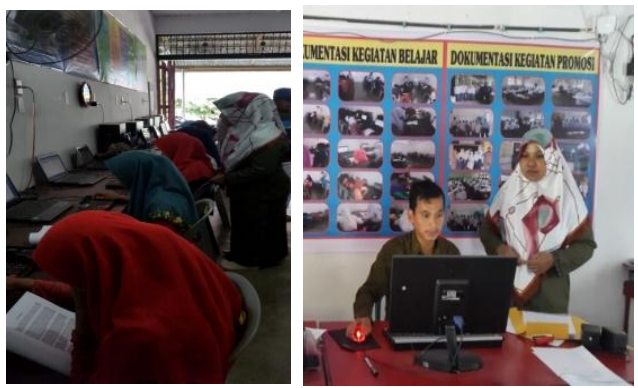

Gambar 3 Training dan pemberian Materi

\section{SIMPULAN}

Berdasarkan kegiatan pengabdian kepada masyarakat yang dilakukan pada Lembaga Kursus Pendidikan (LKP) Mandiri Computer dapat disimpulkan bahwa:

1. Kegiatan pengabdian kepada masyarakat yang dilakukan oleh Tim kegiatan (dosen dan mahasiswa STMIK Royal Kisaran) tepat pada sasaran. Materi kegiatan yang diberikan kepada peserta dapat digunakan dan dimanfaatkan untuk memperluas wawasan penggunaan aplikasi perkantoran yang dasarnya sudah mereka kuasai.

2. Materi yang disampaikan kepada peserta mencapai $90 \%$ dari semua konsep multimedian dan media pembelajaran. Penyampaian materi terdiri dari beberapa sesi, yaitu: penjelasan, praktek, dan diskusi.

3. LKP Mandiri Computer telah memiliki fasilitas laboratorium komputer yang baik. Tim pengabdian sangat terbantu dengan peminjaman fasilitas tersebut. Tim pengabdian hanya menyediakan satu buah infokus untuk menampilkan slade presentasi.

\section{DAFTAR PUSTAKA}

Arsyad, A. (2011). Media pembelajaran. Jakarta: PT Raja Grafindo Persada

Budiman, Permana. 2014. Microsoft Office Power Point. Yogyakarta: Elex Media

Hamadin. 2015. "Pengembangan Media Pembelajaran Interaktif Berbasis Tik Dengan Pendekatan Saintifik." Journal of Physics Learning 3(2): 51-62.

http://jurnal.fkip.unila.ac.id/index.php/J PF/article/view/8207.

http://www.academia.edu/download/57 968682/Jurdimas_Arridha_ZS_Ja n_2018_Fix.pdf

Khotimah. 2008. Media Pembelajaran. Yogyakarta: CV Andi Offset.

Naz, Ahsan Akhtar. 2008. "Use of Media for Effective Instruction Its Importance : Some Consideration." 18: 35-40.

Sutirman, M. P. (2013). Media dan model-model Pembelajaran Inovatif. Yogyakarta: Graha

Syah, Arridha Zikra, Yessica Siagian, Norenta Sitohang, and Ahmad Muhazir. 2018. "Pelatihan Media Pembelajaran Interaktif Berbasis Multimedia Bagi Guru-Guru Sman 02 Tanjungbalai." Jurdimas 1(1): 1-6. 